\title{
AFCI Repository Impact Evaluation Report Systems Analysis Progress Report - FY03
}

W. G. Halsey

U.S. Department of Energy

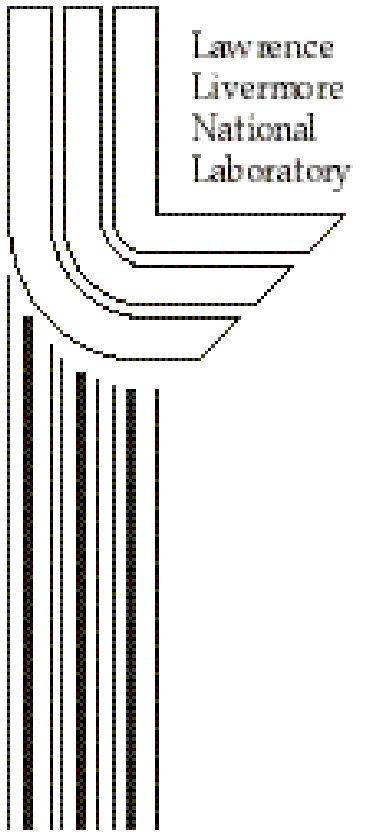

September 12, 2003 


\section{DISCLAIMER}

This document was prepared as an account of work sponsored by an agency of the United States Government. Neither the United States Government nor the University of California nor any of their employees, makes any warranty, express or implied, or assumes any legal liability or responsibility for the accuracy, completeness, or usefulness of any information, apparatus, product, or process disclosed, or represents that its use would not infringe privately owned rights. Reference herein to any specific commercial product, process, or service by trade name, trademark, manufacturer, or otherwise, does not necessarily constitute or imply its endorsement, recommendation, or favoring by the United States Government or the University of California. The views and opinions of authors expressed herein do not necessarily state or reflect those of the United States Government or the University of California, and shall not be used for advertising or product endorsement purposes.

This work was performed under the auspices of the U. S. Department of Energy by the University of California, Lawrence Livermore National Laboratory under Contract No. W-7405-Eng-48.

This report has been reproduced directly from the best available copy.

Available electronically at http://www.doc.gov/bridge

Available for a processing fee to U.S. Department of Energy

And its contractors in paper from

U.S. Department of Energy

Office of Scientific and Technical Information

P.O. Box 62

Oak Ridge, TN 37831-0062

Telephone: (865) 576-8401

Facsimile: (865) 576-5728

E-mail: reports@adonis.osti.gov

Available for the sale to the public from

U.S. Department of Commerce

National Technical Information Service

5285 Port Royal Road

Springfield, VA 22161

Telephone: (800) 553-6847

Facsimile: (703) 605-6900

E-mail: orders@ntis.fedworld.gov

Online ordering: http:/ / www.ntis.gov/ordering.htm

\section{OR}

Lawrence Livermore National Laboratory

Technical Information Department's Digital Library

http:/ / www.llnl.gov/tid/Library.html 
Advanced Fuel Cycle Initiative

\section{$\underline{\text { AFCI Repository Impact Evaluation Report }}$ \\ Systems Analysis Progress Report - FY-03}

September 12, 2003

W. G. Halsey

Lawrence Livermore National Laboratory 


\title{
AFCI Repository Impact Evaluation Report Systems Analysis Progress Report - FY-03
}

\begin{abstract}
Workscope: This activity will assess the waste management benefits from AFC, specifically both short and long term benefits for the U.S. geologic repository program. This includes quantitative evaluation of repository issues (heat load and thermal management, mass and volume, radiotoxicity and dose, waste form optimization, etc.) where AFC can provide the technical basis for improvements in cost, capacity and performance for a repository, and the technical potential to defer the need for additional repositories. Supporting analysis will be obtained from ANL, LANL and SRS for inclusion into an Interim Report that will serve as input to the "Integrated Modeling" and "Economic Analysis" activities, and a Final Report that will document the results of the activity. This activity will endeavor to establish cooperation with DOE-OCRWM to establish mutual understanding of potential repository impacts.
\end{abstract}

\section{Introduction}

A major motivating factor for developing advanced nuclear fuel cycle (AFC) technologies is the potential for improvements in the long-term management of radioactive waste. It is widely understood that compared to a once-thru fuel cycle, it is possible to generate far less waste, and potentially easier waste to manage, with advanced fuel cycles. However, the precise extent and value of these benefits are complex, difficult to quantify, and subject to wide variety of opinion. As AFC costs also contain significant uncertainty, the cost/benefit trade-off and ultimate value of advanced fuel cycle development is still unknown. This document represents a status report of efforts within AFCI Systems Analysis to define and quantify the AFC benefits to geologic disposal. The primary analysis of repository benefits was conducted and reported by $\mathrm{ANL}^{1}$. In addition, efforts for cooperative evaluation of AFCI repository benefits with DOE Office of Civilian Radioactive Waste Management (DOE-RW) progressed with preparation of a draft MOA and receipt of an initial DOE-RW contractor report.

\section{Waste Management Benefits Discussion}

The benefits to radioactive waste management from AFC technology include waste reduction through recycle of material and transmutation in reactors or transmuters, optimization of waste forms, improved efficiency, capacity or performance in repository design and operation, and waste management simplification through separation into more readily managed fractions. These benefits can be discussed in terms of waste management in general, geologic disposal in a 
generic repository, and specific repository benefits such as for a Yucca Mountain (YM) like repository.

\section{$\underline{\text { General Geologic Disposal Benefits }}$}

AFC impacts geologic disposal through dramatic changes in the form and radionuclide inventory in the waste to be disposed of. Spent fuel is processed and selected components recycled or managed separately, instead of being disposed of directly. Removal of most of the uranium and transmutation of some or most of the actinides normally present in SNF into fission products dramatically alters disposal requirements.

AFC impacts on geologic disposal can grouped into four broad catefories:

A) Repository capacity as determined by thermal design goals.

B) Repository performance in terms of radionuclide isolation and long term safety

C) Proliferation risk reduction through reduction is fissile content.

D) Impacts on design flexibility and licensing confidence.

These categories can be used to organize analyses and develop metrics that may be used in system trade studies to optimize AFC technology R\&D.

\section{Repository Thermal Load and Capacity}

Management of the thermal output from spent nuclear fuel (SNF) and high-level radioactive waste (HLW) represents a major design constraint for the repository. This heat generation would be strongly modified by AFC processing. Unfortunately, there is no single and simple thermal design parameter that can be used universally as a measure of benefit to geologic disposal. Waste package design includes internal structures for heat transfer, and there are design constraints on temperatures for the cladding, waste package surface, host rock wall and all the way to the ground surface above the repository. For the inventory envisioned for the U.S. geologic repository, fission product decay (primarily Cs-137 and Sr-90) dominate the thermal output for about the first 80 years. At longer times, actinide decay dominates the thermal output, progressing through a series of actinides from shorter to longer half-life (Pu-238, Am-241, Pu240, 239). Changes to the radionuclides in the waste streams from AFC have a major impact on the thermal response of a repository. In particular, AFC systems with a fast neutron spectrum can fission most of the actinides, resulting in more fission products, but very little actinide inventory. This would skew the thermal output curve strongly to the early years. In addition, the fission products spend a significant residence time in the AFC system, thus allowing for more decay. With removal of the long-lived actinide heat, and viable options for short-term cooling, AFCs provide a great deal of flexibility in thermal management that does not exist for direct disposal of spent fuel. This flexibility has potential benefits for repository design and capacity, waste package design, repository operations and long term performance.

Repository thermal limits for waste package loading and the repository operating period are primarily driven by fission product decay. Normalized per unit thermal energy produced, it scales primarily with in-core residence time and SNF cooling time. Recycle of Pu as MOX fuel can add additional minor actinide thermal load. It has been proposed to separate the high heat 
load fission products separately in various AFC systems. This could be done either through interim storage to permit substantial decay, or through design of a separate repository section specially for high heat load wastes.

Longer-term thermal limits such as peak rock temperatures and maintenance of sub-boiling drainage zones are controlled primarily by actinide decay. Many AFC scenarios produce waste with significantly less plutonium and americium. This could translate directly into increased potential capacity for a given repository size.

Initial thermal capacity benefits for various AFCI Series-I scenarios have been evaluated and reported separately ${ }^{1}$, and are summarized in a later section of this report.

\section{Repository Performance}

Removal of most of the uranium and transmutation of most of the actinides normally present in SNF into fission products dramatically reduces the source term and offers improvement in the long-term performance of a repository. Fabrication of the original fission products and residual actinides lost during AFC processing into optimized waste forms offers the potential for longer radionuclide isolation.

In terms of performance metrics for a YMP like repository, it is best to base the impact of AFC on the performance measure used by the repository program itself. The regulatory requirements and the licensing safety case are based on estimates of future potential doses to a nearby population. This estimate is radionuclide specific and currently comes from complex performance assessment calculations involving mechanistic and stochastic representations of the various features, events and processes envisioned for the future evolution of the repository following permanent closure. For future design trade studies and programmatic decisions, detailed performance assessment calculations of AFC waste streams and repository design alternatives will probably be needed. However, for screening purposes and general guidance, a simpler set of metrics and goals may be developed based on information extracted from published performance assessments for the potential Yucca Mountain Repository.

The dose calculations are radionuclide specific and account for initial inventory, decay, waste form degradation, aqueous solubility, transportation and retardation processes through various exposure pathways, and biological effect. It is therefor difficult to extrapolate results from one radionuclide to another. From YMP analyses, it is seen that different radionuclides dominate the dose at different times after repository closure. Tc-99 dominates up to about 50,000 years, after which Np-237 becomes the largest contributor to dose. The onset and shape of the initial dose rise is determined primarily by waste package lifetime and transport times to the accessible environment.

The current U.S. regulatory guidance for geologic disposal of SNF/HLW, in EPA 40CFR $197^{2}$, specifies a dose limit of 150 microsieverts CEDE (committed effective dose equivalent) per year for a period of 10,000 years. While this translates to 15 millirem/year, the CEDE approach is considered approximately equivalent to a 25 millirem/year whole body dose. The dominant 
radionuclide in the YMP PA calculations during the first 10,000 years is Tc-99, closely followed by I-129. These two radionuclides are characterized by significant inventory, long half-life, high solubility, rapid release from the engineered barrier system (EBS) and little or no sorption during transport. During the 10,000-year regulatory compliance period, the performance impact of AFC is directly proportional to changes in the inventory and EBS release rate of these isotopes.

The peak dose, which occurs at about 300,000 years is dominated by Np-237, followed by $\mathrm{Pu}$ 242 about a factor of about 5 to 10 lower. These actinides are characterized by significant inventory, high radio-biological effect, long half-life, moderate solubility, slower release from the EBS and significant retardation during transport. The ability of AFC to destroy the majority of these actinides would be directly reflected in reductions in peak dose.

In terms of repository performance metrics for AFC, there are several issues that make simple and clear quantitative values difficult to specify. The repository base case calculation currently meets the proposed regulatory criteria during the 10,000 year regulatory period, due in large part to slow and distributed failure of the waste packages. During this period, the primary concern is Tc-99 inventory and release rate. Once about $60-80 \%$ of the Tc dose is moderated, the I-129 becomes dominant. The primary effect is on enhanced confidence in the repository safety argument and an alternative to reliance on the engineered waste packages. The quantitative value to assign to such a qualitative effect is likely to remain open for debate. If Tc and I are not transmuted in the AFC system, then the initial inventories will increase due to the added fission products formed from fission of the actinides (perhaps a 10-15\% increase). If Tc and I are transmuted, then inventory reduction can be a primary metric. In either case, containment of these two fission products within a robust engineered waste form could result in significant performance benefit. This benefit would require waste forms with alteration and leach rates significantly lower than for irradiated UO2 in spent fuel. If waste form leach rates are very low, it is possible for this metric to dominate that of inventory reduction. If the release rate from the EBS is slow compared to 10,000 years, then waste form integrity could dominate repository regulatory compliance. Acceptable demonstration of very low alteration and leach rates will require extensive testing and model development.

Reduction in Np inventory is an important goal for AFC because of the opportunity to reduce the peak dose. The value of this reduction is subject to differing opinions for different reasons than the fission products discussed above. The proposed regulatory period of 10,000 years does not capture the importance of the Np-237 dose contribution. In addition, while the TSPA-VA base case dose was well below the proposed regulation for much more than 10,000 years, it eventually rises to roughly an order of magnitude above the limit. The importance of this is subject to ones perspective, some people believe that this long term calculated dose is a severe safety, public perception and licensing problem, others dismiss it as beyond the regulatory period. In addition, these dose results are thought to be conservatively bounded, and there is some expectation that refined data and models will reduce the Np-237 dose rate by one or several orders of magnitude. The actinides have another complication in that under some repository environmental and water flow scenarios their release rate is solubility limited rather than inventory limited. In that case, significant reduction in inventory might be needed before EBS release rates are reduced. Despite these ambiguities, there seems to be general agreement that significant reduction in the $\mathrm{Np}$ 
inventory would be a major benefit to the repository safety argument. It is always a good thing to reduce the largest contributor to population dose, particularly a dose that rises well above the proposed regulatory limit, albeit after the regulatory time period! To achieve full value, a reduction is also required in inventory Am-241, which decays into Np-237 with a 450 year halflife. It might prove worthwhile to take credit for a robust waste form for the residual actinides, but the extremely long time frames required make this more difficult than for the fission products. Alteration and leach rates would have to be slow on the million-year scale.

There are a number of other potential benefits to the repository from AFC that could influence long term isolation performance. These include further optimization of waste forms, heat management, waste package design optimization, criticality control, repository capacity and the number of waste packages needed and thus the total water flux contaminated. Specific performance based metrics are difficult to define for these issues at this time.

\section{Proliferation Risk}

Proliferation risk from geologic disposal of spent fuel is subject to debate and wide difference in opinion. The proposed repository inventory for Yucca Mountain includes several hundred tons of reactor grade plutonium distributed over 63,000 tons of CSNF. The desirability as well as the accessibility of this material is both important and controversial. While it is acknowledged that reactor grade $\mathrm{Pu}$ might be usable to produce a nuclear explosive, it is considered undesirable for proliferation of militarized weapons. Accessibility is limited by the deep geologic setting, the heat and radiation generated by spent fuel and by the fuel form itself. However, the isotopic desirability and the accessibility both improve with time, potentially resulting in a more attractive material in the distant future. This has resulted in some characterizing a spent fuel repository as the "plutonium mine of the future". In addition to $\mathrm{Pu}$ in CSNF, other potentially attractive nuclear materials are scheduled or at least considered for geologic disposal, including high enrichment uranium fuels, immobilized excess weapon grade plutonium and significant quantities of other fissile actinides.

Fuel cycles that include fast spectrum reactors or transmuters have great leverage over the fissile materials because of their large fission cross sections. Achieving at least an order of magnitude reduction in fissile material inventories nearly eliminates arguments of proliferation risk at the repository. Not only is the attractive material severely reduced in quantity, but it is also mixed with a larger fraction of non-fissile isotopes. Since the repository proliferation risk is not well quantified, weighting a proliferation metric may be difficult. However, two simple metrics to represent proliferation risk reduction are suggested. One is the order of magnitude of fractional reduction in $\mathrm{Pu}-239$ inventory sent to the repository. The other is the similar reduction in total transuranic (TRU) inventory. In terms of public perception, reduction in plutonium inventory (both in society in general and at the repository in specific) is probably the most immediately identifiable benefit from an AFC. 


\section{Repository Design \& Licensing}

Processing SNF provides the repository program potential benefits in a variety of design and licensing areas. While most of these are difficult to quantify, they represent real benefits and warrant continued discussion.

The potential for a criticality event in or near a geologic spent fuel repository has been the subject of considerable debate and analysis over the past decade. While the circumstances that could lead to criticality generally seem to be quite low probability and the consequences limited, the issue continues to be raised. In response, the Yucca Mountain Program continues to invest resources in criticality and consequence analysis. In addition, criticality control places constraints on waste package design and includes engineered criticality control materials. If most of the fissile material is removed from the repository inventory, criticality becomes a nonissue. With criticality scenarios already requiring unlikely conditions and processes to approach feasibility, reduction of the fissile inventory by one or more orders of magnitude would make them implausible or even impossible. The impact of eliminating criticality concerns would be primarily in public perception and licensing confidence. An additional benefit would occur in eliminating design and material performance requirements.

Other design impacts include alteration of the shape and volume of the waste, potential for custom waste form development and homogenization of the waste streams. Processing spent fuel immediately removes the design constraint of disposing of 5 meter long fuel assemblies, and allows other design aspects to dictates waste package size, shape and content. Removal of the uranium to another disposition path eliminates more than $90 \%$ of the mass and much of the volume. The final mass, volume, physical form, thermal and radiation properties of the waste steams are yet to be determined, but there exists a great deal of flexibility to accommodate repository optimization. The long-term isolation benefit from optimized waste forms was discussed previously as a performance benefit. The waste streams from AFC could also be more homogeneous than the currently range of CSNF, DSNF and HLW for which constrain the current repository design.

\section{Impact on Need for Additional Repositories}

From the preceding discussion it is clear that use of AFC could expand the technical capacity limits for a given geologic repository significantly, and thus permit more use of nuclear energy with fewer repositories. An important motivation for AFC R\&D in the U.S. is the potential to defer additional repositories through effective combination of AFC and evolution of the initial repository, or through parallel development of AFC and a high capacity AFC-waste second repository.

The current capacity for the YM repository is set by legislation at 70,000 metric tons of initial heavy metal equivalent, until such time that a second repository is developed. This limit is set below the expected SNF total from current reactors specifically to force consideration of a second repository. The Nuclear Waste Policy Act - as Amended ${ }^{3}$, specifies that the Secretary of Energy shall report to the President and the Congress on the need for a second repository in the 
2007 to 2010 timeframe. Development of AFC technology can provide the technical basis for deferral of a second repository, if Congress chooses to reconsider the legislated capacity limit. Defining this technical capacity benefit is a primary objective of the AFCI Systems Analysis effort.

\section{Current AFCI Repository Benefit Analyses}

Specific AFCI analyses for repository benefit in FY-03 included repository thermal and performance analysis (see ANL-AFCI-089). In addition, potential benefits to geologic disposal were an input to a number of other AFCI activities during the year.

\section{Systems Studies/ANL Analysis}

The primary AFCI repository benefit analysis for FY-03 is reported in "Repository Benefit Analysis - Series 1 Impact", (ANL-AFCI-089) ${ }^{1}$. The summarized conclusions of that analysis is repeated below:

"During FY03, modeling was developed and verified that would allow simulation of the impact of Series 1 fuel cycles on the Yucca Mountain repository. Models were developed for calculating the transient thermal behavior of the repository and for calculating the estimated peak dose rate associated with releases from the repository. Using these models, the following general conclusions were reached:

1. The thermal performance of the repository is determined at present by the long-term heating from the decay of certain actinide elements. Removal of these elements from the waste stream allows an increase in the linear loading of the repository by a factor of 2-3, with the repository now limited by the short term heating from fission products. Removal of the fission products in addition to the actinide elements allows the linear loading to increase greatly, by a factor of 2060, depending on the efficiency of both actinide and fission product separation.

2. Removal of fission products only from the spent fuel results in no increase in the linear loading of the repository, but would allow earlier closure of the repository. The waste packages would be substantially cooler, allowing easier handling. The lower radiation field may also provide other operational benefits.

3. The use of once-through MOX fuel provides no increase in the linear loading of the repository, although it does reduce the amount of plutonium in the waste stream by about 35\%. There is a slight increase in isotopes responsible for the long-term peak dose rate. Estimates of the change in peak dose rate indicate that there is essentially no change in the long-term peak dose rate.

4. Use of multi-recycle strategies can result in significant decreases in the long-term peak dose rate, possibly up to a factor of 60. The impact on the linear loading for the repository has not been determined."

\section{$\underline{\text { Separations Criteria }}$}

How to maximize repository benefit and trade those benefits against other system parameters was a focus of the AFCI Separations Group effort to develop "Separations Criteria". The results of repository impact input to this effort are summarized as:

- Primary repository benefits all depend on reductions in $\mathrm{Pu}, \mathrm{Np}, \mathrm{Am}$.

Capacity (long-term thermal load), Performance (peak dose reduction), Long-term proliferation resistance.

- Recommended separation efficiencies depend on recycle scenario 
For series 1 with single or few $\mathrm{Pu}$ cycles the repository benefit remains limited by MOX fuel disposal, 90\% separation efficiencies would be adequate.

$\square$ For multi-recycle and Series 2 there is the potential to gain greater benefit with increasing separations efficiency up to $\% 99-99^{+} \mathrm{Pu}$ and $\% 95-99$ actinide separation. At these separation efficiencies, further cost/benefit evaluation would be needed.

- $\mathrm{Cs} / \mathrm{Sr}$ management offer benefits primarily to the repository operations.

(- With some actinide reduction, $90 \% \mathrm{Cs} / \mathrm{Sr}$ separation is beneficial.

$\square$ With multi-recycle and Series 2, 97-99\% separation could be beneficial. At these separation efficiencies, further cost/benefit evaluation would be needed.

- Long-lived fission products, primarily Tc-99, and secondarily I-129 control the performance of a YM-type repository for the U.S. regulatory compliance period of 10,000 years.

$\square$ Current performance is sufficient.

$\square$ Separation/transmutation, while possible, does not appear to justify cost.

Recommendation to dispose in an optimized, robust waste form.

- There is an ongoing need for quantifiable metrics for evaluating system trade-offs.

$\underline{\text { Scenario Analysis }}$

AFCI Systems Analysis conducted a "Scenario Study" that evaluated a number of technology deployment alternatives. Among the purposes of the study was evaluation of geologic repository impacts from different technology deployments. The study used accumulation of SNF, plutonium and minor actinides as representative performance measures for scenarios. The repository impact conclusions from the study are summarized as:

- Continued use of nuclear energy at current capacity generates four Yucca Mountain equivalent (YMe) loads of SNF by 2100, maintaining current fractional contribution generates 7 YMe loads.

- Commitment to AFC, second repository or massive indefinite storage will be needed early during deployment of new plants (2010-2020)

- Based on long-term heat load limits, AFC deployment can defer need for additional repository capacity. MOX recycle delays but does not greatly reduce thermal load, but multi-recycle can provide several-fold improvements in long-term repository thermal load limits.

- Only fast spectrum systems can actually reduce total inventories of plutonium and minor actinides

- There is an ongoing need for quantifiable metrics for evaluating system trade-offs.

\section{$\underline{\text { Proposed Quantitative Measures }}$}

From the earlier Waste Management Benefits Discussion, it is clear that there is not a single and simple metric for 'repository benefit' that would be agreed to by all interested parties. However, it is also clear that some way to quantify such benefits is needed for AFCI system trade studies and optimization. Initial efforts to produce such a working 'quantitative repository benefit measure' have been started. Based on the thermal limit analysis discussed above, two initial measures are proposed: 
- Integrated thermal output of the waste from 100 to 2000 years out of reactor, to address long-term geothermal limits.

- Thermal output of the waste at 100 years out of reactor, to address the repository operational period, and specifically the heat output at time of repository backfill/closure.

Further metrics will be developed as indicated by analysis and interaction with the repository program. Eventually, quantitative weighting factors will be proposed to combine these metrics to provide a 'repository benefit score'.

\title{
Interface With DOE-OCRWM
}

From the preceding discussion, it is clear that the impacts of AFCI on the U.S. geologic repository program are of mutual interest to DOE-NE and DOE-RW. Because of this, cooperation between the two programs is being pursued to develop and mutually beneficial and understood position. A draft Memorandum of Agreement has been prepared and is in review at the interested DOE offices. The draft background statements illustrates the intent of this cooperation:

\begin{abstract}
Background: It is recognized that $R W$ has a focused mission and specific mandate to provide for the safe geologic disposal of spent nuclear fuel and high-level radioactive waste. Until such time that advanced fuel cycles become part of the commercial nuclear fuel cycles in the United States, the repository program must proceed based on existing and projected waste streams.

It is also recognized that $N E$ has a newly established advanced fuel cycle program to develop advanced fuel treatments technologies. Successful deployment of these technologies could result in significant changes in future waste streams destined for geologic disposal and thus, could impact many aspects of future repository design, operation, and performance.

Therefore, it is both wise and prudent for $R W$ and $N E$ to cooperate in the evaluation of the potential interactions of these two programs. This cooperation should seek to enhance opportunities that mutually benefit both programs."
\end{abstract}

The Nuclear Waste Policy Act - As Amended ${ }^{3}$ requires DOE to report to the President and the Congress sometime in the 2007 - 2010 timeframe on the need for a second geologic repository. As seen in the analysis above, a successful AFC development and deployment could have a major impact on this need. The DOE offices are exploring the potential for AFCI to contribute to the technical basis for this report.

As an initial step toward cooperation, DOE-RW has tasked their technical services contractor (Booze-Allen-Hamilton (BAH)) to begin initial analyses of impacts and potential cost savings to the repository resulting from processing spent fuel in an AFC as compared to direct disposal. The YMP baseline is being used for comparison.

\section{DOE-RW Contractor Analysis}

An initial DOE-RW contractor report "Repository Baseline for Analysis of Interactions with the Advanced Fuel Cycle Initiative Program"4 has been prepared and is currently in review by AFCI staff. The report includes description of a repository baseline design, cost and performance, and initial differential cost analysis of limited diversion of spent fuel from direct disposal into 
processing and limited recycle. The baseline information is a useful starting point for cooperative studies, for example providing baseline thermal loading of $1.42 \mathrm{~kW} / \mathrm{meter}$, drift costs at $\$ 2000 / \mathrm{ft}$, waste package costs at $\$ 400 \mathrm{~K}$ each and one potential expansion capacity estimate of approximately 140,000 Mt of SNF. However, some of the underlying assumptions should be updated to be more consistent with the AFCI mission. Staff from AFCI and BAH are developing revised input for this revision. Future analysis may delve into scenarios beyond perturbation analysis and consider major changes in future fuel cycle technology.

\section{Benefits Status Summary and Path Forward}

Systems analyses of potential repository benefits from AFC scenarios have been conducted and coordinated with separations and transmutation system studies.

- With effective removal of actinides, AFC can significantly impact repository technical capacity measured against thermal design limits. $\mathrm{Cs} / \mathrm{Sr}$ management becomes most valuable after significant actinide reduction.

- Analyses currently provide comparative benefits. Quantitative metrics are being developed against various geologic disposal parameters.

- Cooperation with DOE-RW is progressing and initial baseline information has been shared.

As the program moves forward, agreement between DOE-NE and DOE-RW on the technical contribution of AFCI to the 2007-2010 report on the need for a second repository will become more important. Definition of this contribution, and progress on coordinating this analysis with other AFCI activities, will build upon the recent system studies, repository benefits analysis and developing YMP interface.

\section{References}

1) "Repository Benefit Analysis - Series 1 Impact", R. A. Wigeland, T. H. Bauer, T. H. Fanning, E. E. Morris, ANL-AFCI-089, Argonne National Laboratory, Argonne, Il., August, 2003.

2) "Public Health and Environmental Radiation Protection Standards for Yucca Mountain, Nevada", U.S. Environmental protection Agency, 40CFR Part 197.

3) "The Nuclear Waste policy Act of 1982 - As Amended", Title I, Subtitle E, Section 161, Public law 97-425, 96 Stat. 2201 (and amendments P.L. 100-203, P.L. 100-507, P.L. 102486), 42 U.S.C. 10101 and following.

4) "Repository Baseline for Analysis of Interactions with the Advanced Fuel Cycle Initiative Program", Pre-Decisional Study, HGQ-ST-03-02C-001, Booz, Allen, Hamilton, Washington, DC., June, 2003. 


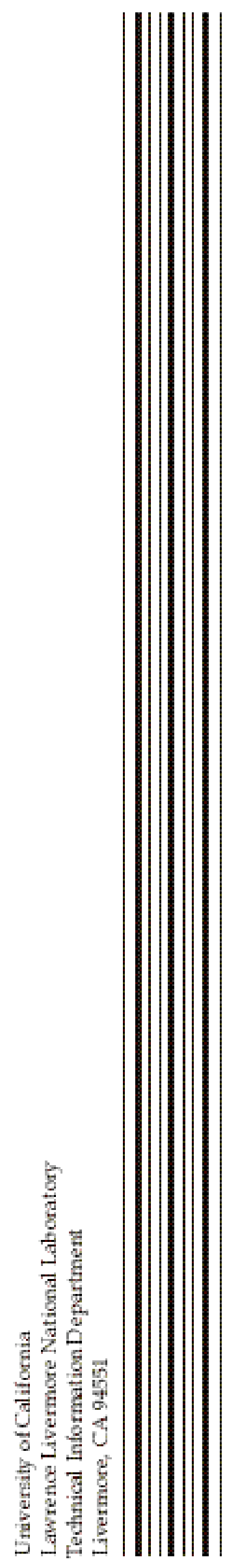

